\title{
Article
}

https://doi.org/10.11646/phytotaxa.394.3.3

\section{Boswellia occulta (Burseraceae), a new species of frankincense tree from Somalia (Somaliland)}

\author{
MATS THULIN $^{1 *}$, ANJANETTE DECARLO ${ }^{2} \&$ STEPHEN P. JOHNSON ${ }^{2}$ \\ ${ }^{1}$ Systematic Biology, Department of Organismal Biology, EBC, Uppsala University, Norbyvägen 18D, SE-752 36 Uppsala, Sweden. \\ ${ }^{2}$ Aromatic Plant Research Center, 230 N 1200 E, Suite 100, Lehi, UT 84604, USA. \\ *Author for correspondence: E-mail: mats.thulin@ebc.uu.se
}

\begin{abstract}
The new species Boswellia occulta is described from a small area in the Ceel Afweyn District of Somaliland (northwestern Somalia), where it is locally of considerable socio-economic importance. Although used for frankincense production by many generations of local harvesters, it has been unknown to science until now. Apart from the recently collected type material, it is also known from a sterile and hitherto misunderstood collection made in 1945. The simple-leaved Boswellia occulta is morphologically compared with $B$. sacra and B. frereana, the two major frankincense-producing species in the region, both with imparipinnate leaves, and it appears to be most closely related to B. sacra. The new species is the only simpleleaved species of Boswellia known outside Socotra.
\end{abstract}

\section{Introduction}

Within the ongoing Conserve the Cal Madow project (www.conservecalmadow.org) in Somaliland (northwestern Somalia), resin from different populations of Boswellia sacra Flückiger (1867: 31) and B. frereana Birdwood (1870: 146), the two major frankincense-producing species in the region (Thulin \& Warfa 1987), was collected and chemically analyzed. Among the samples of "beeyo" (the Somali word for the resin of B. sacra), samples from Daba Celdero in the Ceel Afweyn District stood out by having essential oils dominated by methoxydecane, rather than a standard terpene profile (DeCarlo, unpublished research data). Photographs of trees from which the resin originated were obtained from a local harvester, Ahmed Mohamed Dhunkaal, in August 2018. These could not be identified with certainty and did not seem to agree with either $B$. sacra or $B$. frereana.

However, in October 2018 excellent herbarium material, showing leaves, flowers and fruits, was collected by Ahmed Mohamed Dhunkaal. This clearly demonstrated that the Daba Celdero trees are also morphologically unique. The material now permits description of the Daba Celdero plant as a new species of Boswellia, apparently restricted to a small area within the Ceel Afweyn District, where it is a frankincense-producing species of considerable socioeconomic importance (Ahmed Mohamed Dhunkaal pers. comm.). The collection from Daba Celdero also throws new light on a sterile collection made by Philip Glover and Hamish Gilliland in 1945, from the same locality and clearly of the same species, but up to now misunderstood.

Boswellia Roxb. in Colebrooke (1807: 379) is a genus of about 20 species of trees or shrubs in arid parts of tropical Africa, southern Arabia and India, with the highest concentration of species in the Horn of Africa region (Mabberley 2017). The new species described here further adds to the diversity of the genus in this region.

\section{Taxonomy}

Boswellia occulta Thulin, DeCarlo \& S.P.Johnson sp. nov. (Figs. 1-3)

Type:-SOMALIA (SOMALILAND). Sanaag Region: Ceel Afweyn District, Afdhudhubeed village near Ceel Dibir town, Daba Celdero, elev. 440 m, 12 October 2018, flowering and fruiting, Ahmed Mohamed Dhunkaal s.n. (holotype HARG!; isotype UPS! No. V933191). 
Boswellia occulta differs from B. frereana by its flowers with white (vs reddish or greenish red) petals and tubular (vs flattened) disk, and fruits with 4-5 [vs (5-)6(-8)] locules; and from $B$. sacra by its glabrous (vs \pm densely pubescent) leaves with mostly strongly undulate-sinuate (vs crenate to subentire) margins, and unwinged pyrenes (vs pyrenes often more or less surrounded by a persistent wing); and from both $B$. frereana and B. sacra by its simple (vs imparipinnate) leaves.

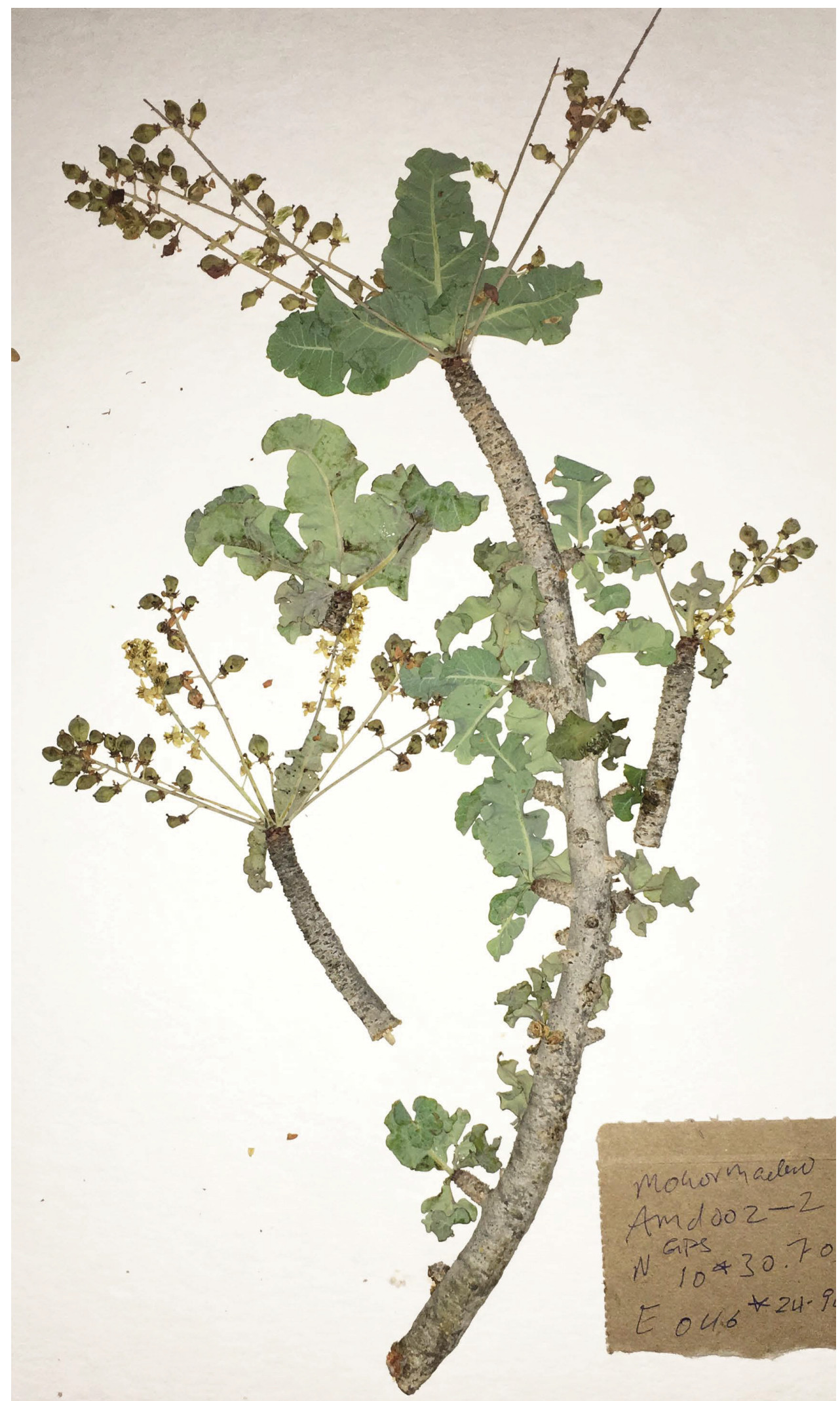

FIGURE 1. Holotype of Boswellia occulta, with field label and still unmounted. Photograph: Stephen P. Johnson. 


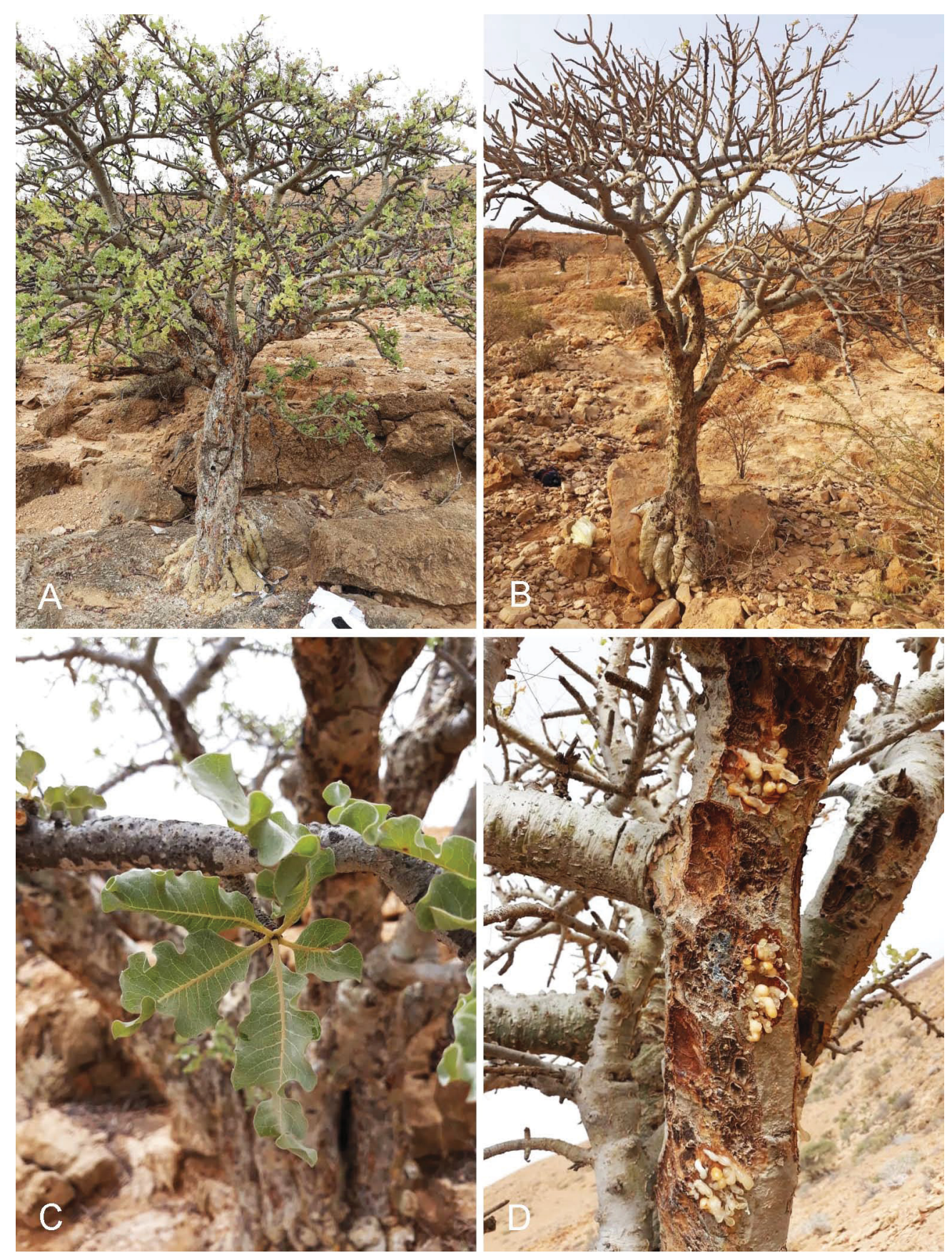

FIGURE 2. Boswellia occulta, from the type locality A. Tree, in leaf; B. Tree, showing swollen disk-shaped base when growing on rock; C. Branches, showing foliage; D. Trunk with incisions, showing resin oozing out. Photographs: Ahmed Mohamed Dhunkaal.

Tree, up to $5 \mathrm{~m}$ tall, branching from the base or with a single distinct trunk; base of trunk \pm swollen and disk-shaped; bark greyish or greyish brown, smooth or somewhat flaking; branches spreading, young shoots glabrous; resin copious, milky, drying pale yellowish brown. Leaves densely crowded at shoot-apices or alternate on young long-shoots, simple, glabrous or minutely glandular along veins above, bluish-green; blade 40-120 $\times 20-45 \mathrm{~mm}$, elliptic-oblong, cuneate to truncate at the base, obtuse at the apex, with mostly strongly undulate-sinuate margins, sometimes lobed to the midrib or almost so; midrib prominent, lateral veins $10-15$, tertiary venation reticulate; petiole 5-20 mm long. Flowers bisexual, produced with the leaves, in 10- to 20 -flowered racemes, up to $80 \mathrm{~mm}$ long, clustered at ends of short-shoots; peduncle 15-20 mm long, glabrous, sulcate; rachis glabrous, sulcate; pedicels 2-5 $\mathrm{mm}$ long, glabrous; bracts ovate, apiculate, ca. $1 \mathrm{~mm}$ long, ciliate; bracteoles inserted near middle of pedicels, linear-lanceolate, ca. $0.5 \mathrm{~mm}$ long, ciliate. Calyx cup-shaped, ca. $1.5 \mathrm{~mm}$ long, with 5 short, broadly triangular, obtuse to subacute lobes, glabrous except for minutely ciliate margins. Petals 5 , white, $4-5 \times 2.0-2.5 \mathrm{~mm}$, spreading or reflexed in open flowers, elliptic, with an acute incurved apex, glabrous on outer surface, papillose on inner surface and along margins. Stamens 10, inserted at 
the base of and between the lobes of the disk; filaments 2.0-2.5 mm long, linear, glabrous; anthers ca. $1.4 \mathrm{~mm}$ long, oblong, yellow, glabrous or puberulous. Disk tubular, ca. $1.5 \mathrm{~mm}$ high and ca. $2 \mathrm{~mm}$ in outer diameter, 10-lobed, glandular. Pistil $2.5-3.0 \mathrm{~mm}$ long, narrowly ellipsoid, furrowed, glabrous; style 1.0-1.5 mm long; stigma truncate, green. Fruits 4- to 5-locular, 6-8 $\times 4.0-4.5 \mathrm{~mm}$, pyriform, glabrous; pyrenes ca. $3.5 \times 2.5 \mathrm{~mm}$, trullate in outline, aristate at the apex, trigonous, without wing.

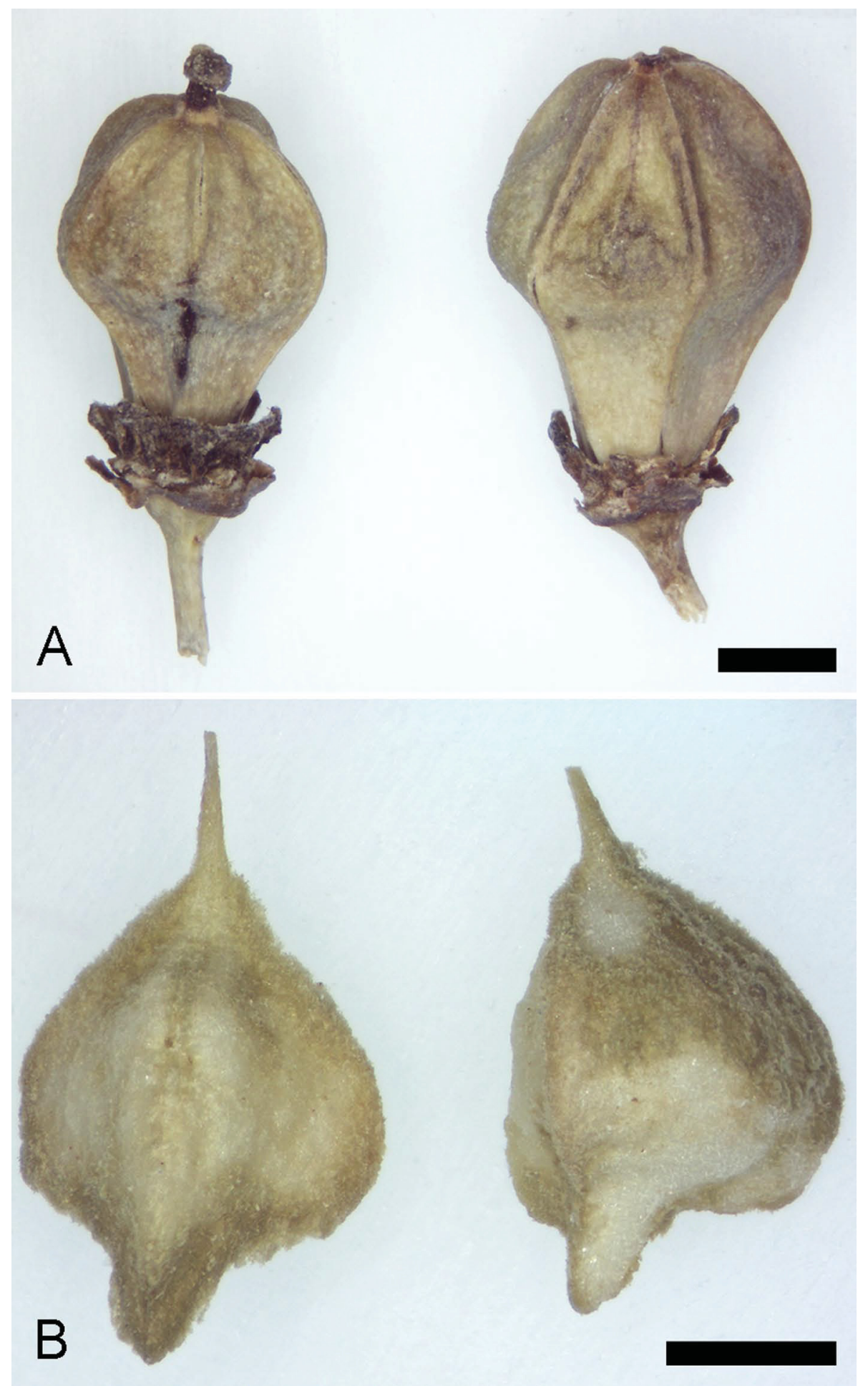

FIGURE 3. Boswellia occulta, from isotype A. Fruits, 4-locular with style intact (left) and 5-locular (right); B. Pyrenes, ventral (left) and dorsal (right) views. Scales $2 \mathrm{~mm}$ (A), $1 \mathrm{~mm}$ (B). Photographs: Henrik Sundberg.

Distribution and habitat:-Boswellia occulta is only known from a small area in northwestern Somalia (Somaliland) (Fig. 4), where it is locally common and the dominant tree on west-facing arid hillsides on limestone at $400-500 \mathrm{~m}$ elevation. The tree usually grows directly on limestone cliffs and boulders, and then has a more or less 
swollen disk-shaped base of the trunk (Fig. 2B). More detailed studies of the extent of the range of the species and the numbers and densities of the trees and their regeneration are planned in the near future.

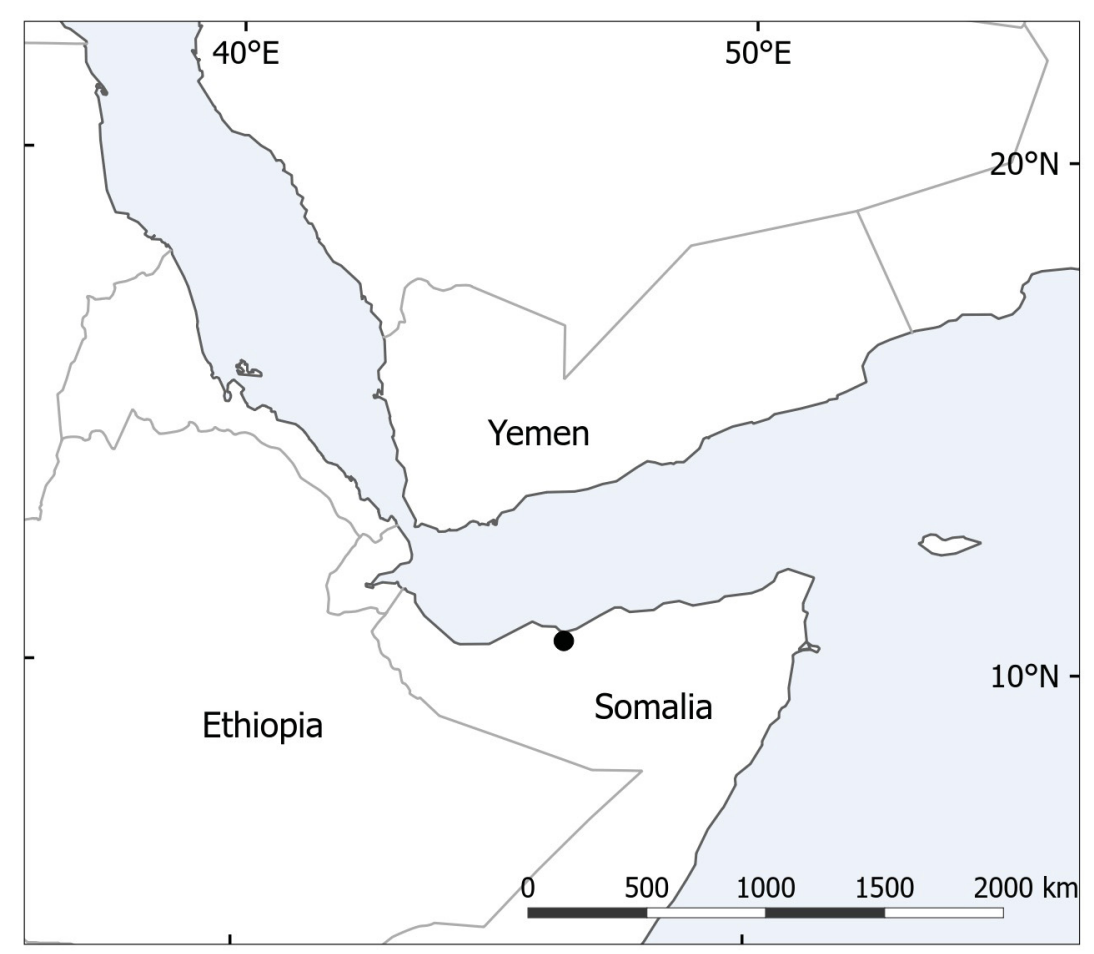

FIGURE 4. Map of Horn of Africa and southern Arabia, showing type locality of Boswellia occulta.

IUCN Red List Assessment:-At present, B. occulta has to be preliminary treated as Data Deficient (DD) under the IUCN Red List Categories and Criteria (IUCN 2012).

Taxonomic remarks:-The only previously known collection of Boswellia occulta, Glover \& Gilliland 719 , is sterile and has been problematic ever since it was collected in 1945. The locality, "Biuyu Mboli", is an old place name, rarely used today, for the type locality of $B$. occulta. The collection was earlier identified as $B$. frereana, mainly because of the markedly undulate-sinuate margins of the leaves. In the accounts of frankincense trees in Somalia by Thulin \& Warfa (1987) and Thulin (2000), it was interpreted as a simple-leaved form of B. frereana, analogous with, for example, the simple-leaved forms of the normally pinnately leaved B. elongata Balfour (1882: 505) on Socotra (Thulin \& Al-Gifri 1996).

When good photographs of the tree (Fig. 2), as well as material of flowers and fruits (Figs. 1, 3), became available, it was immediately clear that this population cannot be just a form of $B$. frereana. Apart from the simple (vs imparipinnate) leaves (Fig. 1, 2C), the flowers with white (vs reddish or greenish red) petals (Fig. 1) and tubular (vs flattened) disk, and the 4- to 5-locular [vs (5-)6(-8)-locular] fruits (Fig. 3A) are distinctive. The white petals, tubular disk, fruits, as well as the habit of the trees are in better agreement with $B$. sacra, and this is likely to be the nearest relative of the new species. Boswellia occulta can be easily separated from B. sacra by its simple (vs imparipinnate) leaves that are glabrous (vs more or less densely pubescent) with mostly markedly undulate-sinuate (vs crenate to subentire) margins, and by its unwinged pyrenes (vs pyrenes often more or less surrounded by a persistent wing).

Outside Socotra, B. occulta is the only known species of Boswellia with simple leaves. On Socotra there are two species, B. nana Hepper (1971: Tab. 3676, p. 1) and B. popoviana Hepper (1971: Tab. 3677, p. 1), which are mostly simple-leaved (Miller \& Morris 2004), although the leaves are not strongly undulate-sinuate as in B. occulta. They are both more slender trees compared to the robust $B$. occulta, and the leaves are puberulous on the nerves above in $B$. nana and lanate beneath in B. popoviana (vs glabrous in B. occulta).

Etymology:-The epithet "occulta" (from Latin "occultus", hidden) refers to the history of this species that, although used for frankincense production by many generations of local harvesters, has been unknown to science until now. 
Vernacular name and uses:-Mohor madow (Somali, fide Glover \& Gilliland 719 and Ahmed Mohamed Dhunkaal s.n.); this is the vernacular name generally used also for B. sacra in Somalia. However, the harvesters in the B. occulta area distinguish between B. occulta ("mohor madow") and B. sacra ("mohor cad", "mohor dadbeed" or "mohor lab"). Frankincense produced from B. occulta (Fig. 2D) has unique properties (DeCarlo, unpublished research data) and is important in the local economy.

Additional specimens examined (paratypes):-SOMALIA (SOMALILAND). Sanaag Region: Biuyu Mboli, 20 February 1945, sterile, Glover \& Gilliland 719 (BM!, EA!, K!).

\section{Acknowledgements}

We are much indebted to Ahmed Mohamed Dhunkaal for photographs and information on Boswellia occulta, as well as for the herbarium material that has enabled the description of the species. Henrik Sundberg is thanked for assistance with the photographs in Fig. 3, and Anders Larsson for assistance with the map in Fig. 4. We thank the Aromatic Plant Research Center for funding for the collection of samples, the curators of BM, EA and $\mathrm{K}$ for access to the historical material of the new species, and two anonymous reviewers for helpful comments on the manuscript.

\section{References}

Balfour, I.B. (1882) Diagnoses plantarum novarum et imperfecte descriptarum Phanerogamarum Socotrensium. Pars prima. Proceedings of the Royal Society of Edinburgh 11: 498-514.

https://doi.org/10.1017/S0370164600047702

Birdwood, G. (1870) On the genus Boswellia, with descriptions and figures of three new species. Transactions of the Linnean Society of London 27: 111-148.

https://doi.org/10.1111/j.1096-3642.1870.tb00205.x

Colebrooke, H.T. (1807) On olibanum or frankincense. Asiatic Researches, or Transactions of the Society 9: 377-382.

Flückiger, F.A. (1867) Lehrbuch der Pharmakognosie des Pflanzenreiches. Naturgeschichte der wichtigeren Arzneistoffe vegetabilischen Ursprunges. Gaertner, Berlin, 748 pp.

Hepper, F.N. (1971) Boswellia nana and B. popoviana. Hooker's Icones Plantarum Ser. 2, 7 (4): Tabs. 3676, 3677.

IUCN (2012) IUCN Red List Categories and Criteria: Version 3.1 ed. 2. IUCN, Gland, Switzerland and Cambridge, UK.

Mabberley, D.J. (2017) Mabberley's plant-book, ed. 4. Cambridge University Press, UK, 1102 pp. https://doi.org/10.1017/9781316335581

Miller, A.G. \& Morris, M. (2004) Ethnoflora of the Soqotra archipelago. Royal Botanic Garden, Edinburgh, UK, 759 pp.

Thulin, M. (2000) Burseraceae. In: Thulin, M. (Ed.) Flora of Somalia, vol. 2. Royal Botanic Gardens, Kew, UK, pp. 183-228.

Thulin, M. \& Al-Gifri, A. (1996) The frankincense trees (Boswellia spp.) on Soqotra. In: Dumont, H.J. (Ed.) Proceedings of the first international symposium on Soqotra Island: present and future. United Nations Publications, New York, pp. 107-113.

Thulin, M. \& Warfa, A.M. (1987) The frankincense trees (Boswellia spp., Burseraceae) of northern Somalia and southern Arabia. Kew Bulletin 42: 487-500.

https://doi.org/10.2307/4110063 